\title{
Characteristics of ischemic stroke and intracranial hemorrhage in patients with nephrotic syndrome
}

\author{
Wen-Yi Huang ${ }^{1}$, Chun-Wei Chang ${ }^{2}$, Chiung-Mei Chen², Kuan-Hsing Chen ${ }^{3}$, Chien-Hung Chang ${ }^{2}$, \\ Hsiu-Chuan $\mathrm{Wu}^{2}$ and Kuo-Hsuan Chang ${ }^{2^{*}}$
}

\begin{abstract}
Background: The incidence of cerebral stroke, including ischemic infarction and intracranial hemorrhage (ICH), increases in patients with nephrotic syndrome (NS). However, the clinical characteristics of patients with NS and stroke remain elusive. We aimed to investigate the clinical presentation and prognosis among patients with NS and ischemic stroke (IS) or $\mathrm{ICH}$.

Methods: We conducted a population-based retrospective cohort study of patients with NS and acute stroke using the Chang Gung Research Database of Taiwan from January 1, 2001, to December 31, 2017. The participants were recruited from the 7 branches of Chang Gung Memorial Hospital.

Results: A total of 233 patients with IS and 57 patients with ICH were enrolled. The median age was 60 (52-70) years. The prevalence rates of hyperlipidemia, hyperuricemia, and smoking were higher in IS than in ICH. IS demonstrated lower white blood cell count $\left(7.80 \mathrm{vs.} 8.92 \times 10^{9} / \mathrm{L}\right)$ and high-sensitivity C-reactive protein level $(33.42$ vs. $144.10 \mathrm{nmol} / \mathrm{L}$ ) and higher cholesterol ( 5.74 vs. $4.84 \mathrm{mmol} / \mathrm{L})$, triglyceride $(1.60 \mathrm{vs} .1 .28 \mathrm{mmol} / \mathrm{L})$, and albumin (24 vs. $18 \mathrm{~g} / \mathrm{L}$ ) levels compared with $\mathrm{ICH}$. The dependent functional status and 30-day mortality were higher in $\mathrm{ICH}$ than in IS. The risk factors for 30-day mortality for patients with NS and stroke were coronary artery disease (CAD), ICH, and total anterior circulation syndrome. The multivariate Cox regression analysis revealed that CAD was positively associated with 30-day mortality in patients with IS (hazard ratio $24.58,95 \% \mathrm{Cl} 1.48$ to 408.90). In patients with ICH, CAD and subarachnoid hemorrhage were positively associated with 30-day mortality (hazard ratio 5.49, $95 \% \mathrm{Cl} 1.54$ to 19.56 ; hazard ratio $6.32,95 \% \mathrm{Cl} 1.57$ to 25.53 , respectively).
\end{abstract}

Conclusions: ICH demonstrated a higher risk of dependence and 30-day mortality compared with IS in patients with NS. Intensive monitoring and treatment should be applied particularly in patients with NS and ICH.

Keywords: Nephrotic syndrome, Stroke, Intracranial hemorrhage, Ischemic stroke, Intracerebral hemorrhage, Subarachnoid hemorrhage

\footnotetext{
* Correspondence: gophy5128@cgmh.org.tw

${ }^{2}$ Department of Neurology, Chang Gung University College of Medicine,

Chang Gung Memorial Hospital, Linkou Branch, 5, Fu Hsing Street, 333

Taoyuan, Taiwan

Full list of author information is available at the end of the article
}

(C) The Author(s). 2021 Open Access This article is licensed under a Creative Commons Attribution 4.0 International License, which permits use, sharing, adaptation, distribution and reproduction in any medium or format, as long as you give appropriate credit to the original author(s) and the source, provide a link to the Creative Commons licence, and indicate if changes were made. The images or other third party material in this article are included in the article's Creative Commons licence, unless indicated otherwise in a credit line to the material. If material is not included in the article's Creative Commons licence and your intended use is not permitted by statutory regulation or exceeds the permitted use, you will need to obtain permission directly from the copyright holder. To view a copy of this licence, visit http://creativecommons.org/licenses/by/4.0/. The Creative Commons Public Domain Dedication waiver (http://creativecommons.org/publicdomain/zero/1.0/) applies to the data made available in this article, unless otherwise stated in a credit line to the data. 


\section{Background}

Nephrotic syndrome (NS) is characterized by the presence of proteinuria, peripheral edema, hypoalbuminemia, and increased risk of both venous and arterial thromboses. An increased risk of cardiovascular diseases has been reported in patients with NS [1]. The hypercoagulable state of patient with NS results from an imbalance between procoagulant/ prothrombotic and anticoagulant/antithrombotic factors, which promotes in situ thrombosis in the deep veins or arteries [1, 2]. Although arterial thrombosis occurs mostly in children, the occurrence of strokes, especially ischemic stroke (IS), is not uncommon in adult patients with NS [3, 4]. Several case reports [3-6] and retrospective cohort studies $[7,8]$ suggest that patients with NS have an increased risk of IS and venous sinus thrombosis.

On the other hand, intracranial hemorrhage $(\mathrm{ICH})$ is also seen in patients with NS [9-11]. This cerebral hemorrhage, which could be associated with intravascular deposition of immune complexes or systemic amyloidosis [12-14], can occur in patients with NS without stroke risk factors $[11,15,16]$. Biochemical abnormalities, such as proteinuria, D-dimer levels, hyperlipidemia, and renal function impairment, are associated with the occurrence of $\mathrm{ICH}$ in patients with NS [11]. However, the small numbers of patients in these studies limit further understanding of the clinical outcome and potential pathogenesis in this subpopulation of patients.

Although lines of evidence suggest that the incidence rates of IS and $\mathrm{ICH}$ both increase in patients with NS, research examining the functional outcome differences in those with IS versus $\mathrm{ICH}$ is limited. It would be important to understand the clinical presentations and outcomes of these patients with both types of stroke by a large cohort study. Using real-world data from the Chang Gung (CG) Research Database, we conducted a retrospective cohort study to investigate the clinical presentations of NS patients with stroke in a large number of patients. To our knowledge, this is the largest study done specifically in NS patients with stroke. The results provide important information to clarify the pattern and outcome of stroke in patients with NS.

\section{Methods}

\section{Ethical standards}

The procedure of this clinical study was performed under a protocol approved by the Medical Ethics Committee of CG Memorial Hospital, Taipei, Taiwan in accord with the Helsinki Declaration of 1975 (the IRB approval number: 202001012B0). As all data were anonymized from existing databases and results were presented in aggregate, the requirement for informed consent was waived. The no requirement of informed consent was approved by the Medical Ethics Committee of CG Memorial Hospital, Taipei, Taiwan.

\section{Data source and collection}

The CG Medical Foundation, which consists of branches of CG Memorial Hospital including two medical centers and two regional and three district hospitals, is the largest medical system in Taiwan [17]. The CG Medical Foundation has 10,070 beds, with admission of more than 280,000 patients each year [18]. All branches of CG Memorial Hospital apply electronic medical records. The CG Research Database is a de-identified database comprised of multi-institutional standardized electronic medical records, dating back to 2000, from the CG Medical Foundation. It contains demographic data, clinical diagnosis, medical records, laboratory data, radiological images, and reports [17].

\section{Study population}

The study subjects were selected based on the CG Research Database from January 1, 2001, to December 31,2017 . The accuracy of the diagnoses of NS and stroke of the subjects was confirmed by the ICD-9-CM or ICD-10-CM codes combined with the records of discharge summary. We only recruited subjects with NS who were admitted for acute IS or nontraumatic $\mathrm{ICH}$.

\section{Clinical assessments of IS}

The IS subtypes were grouped by the Trial of ORG 10, 172 in Acute Stroke Treatment classification system [19], and the clinical subtypes of IS were grouped by the Oxfordshire Community Stroke Project classification system [20]. Comorbidities, vascular risk factors, and clinical course were identified after an in-depth review of the medical records by three board-certified neurologists (Chang $\mathrm{KH}$, Chang $\mathrm{CW}$ and Huang WY). Acute complications during admission were recorded. Laboratory tests including complete blood cell count, blood chemistry and brain imaging studies, coagulation testing, carotid duplex, and transthoracic echocardiography were recorded. The primary end point was 30-day mortality, and every cause of death was reviewed.

\section{Clinical assessments of ICH}

The ICH subtypes were recorded, which included intracerebral hemorrhage (IH), subarachnoid hemorrhage (SAH), subdural hemorrhage, and arteriovenous malformation with hemorrhage. Comorbidities, vascular risk factors, clinical course, and laboratory tests were identified after an in-depth review of the medical records by three board-certified neurologists (Chang $\mathrm{KH}$, Chang CW and Huang WY). The severities of $\mathrm{IH}$ and SAH were evaluated by the IH score [21] and Hunt and Hess scale, respectively. The primary end point was 30-day mortality, and every cause of death was reviewed. 


\section{Statistical analysis}

Continuous variables with normal distribution were expressed as mean \pm standard deviation, whereas those that were not normally distributed were expressed as median (interquartile range). Categorical variables were expressed as a number (percentage) [22]. We used the "mean substitution" method to handle the missing laboratory data [23]. Different groups (IS and ICH) were compared using the chi-square (categorical variables) or Mann-Whitney $U$ (continuous variables that were not normally distributed) or Student's $t$-test (continuous variables with normal distribution) [22]. The characteristics and clinical course of the patients with IS classified by the Trial of ORG 10,172 in Acute Stroke Treatment classification system and patients with $\mathrm{ICH}$ were analyzed using descriptive statistics, and the group differences were assessed using one-way ANOVA (continuous variables with normal distribution) or the Kruskal-Wallis (continuous variables that were not normally distributed) or chi-square (categorical variables) test [22]. The Kaplan-Meier survival analysis was used to estimate the cumulative overall survival for IS and $\mathrm{ICH}$, and the group differences were assessed using the log-rank test [24]. The Cox proportional hazards model was used to determine the significance of each variable in predicting the 30-day mortality. A univariate Cox model, assessing all previously identified variables, was used to measure the hazard ratio for mortality. All variables with $P<0.1$ in the univariate Cox regression analysis entered a stepwise, backward multivariate Cox regression analysis. A backward, stepwise multivariate Cox regression model was also used to identify the risk factors for the 30-day mortality, and the variables with $P<$ 0.05 remained for the final model [24]. All statistical analyses were performed with IBM SPSS statistics 19 for Windows.

\section{Results}

\section{Patient selection}

We recruited in hospitalization records of patients in CG Research Databases from January 1, 2001, to December 31, 2017, using the NS-related ICD-9-CM or ICD-10-CM codes, and 3352 hospitalization records were identified. The selected hospitalized records (include the discharge summary and laboratory data) were screened by the board-certified nephrologist (Chen $\mathrm{KH}$ ) and neurologist (Huang WY, Chang CC and Chang $\mathrm{KH})$. After excluding 1503 patients that did not present with NS, and 1559 patients that are not admitted with the diagnosis of acute stroke, we obtained 290 patients, including 233 patients with IS and 57 patients with $\mathrm{ICH}$, for further analysis (Supplementary Figure 1). The percentage of missing laboratory data ranged from 0 to 15.8 \% (Supplementary Table 1).

\section{Demographic characteristics among patients with any} stroke

A total of 290 patients with NS who had been hospitalized for acute IS $(n=233,80.3 \%)$ or ICH $(n=57,19.7 \%)$ were enrolled in the study. Patient characteristics are presented in Table 1 and Supplementary Table 2. The median age was $60(52-70)$ years. The prevalence rates of hyperlipidemia (63.9\%), hyperuricemia (17.2\%), and smoking (9.4\%) in patients with IS were significantly higher than in those with ICH (hyperlipidemia, $29.8 \%$, $P<0.001$; hyperuricemia, $7 \%, P=0.037$; smoking, $1.8 \%$, $P=0.037$ ). In laboratory data, patients with $\mathrm{ICH}$ demonstrated higher white blood cell (WBC) count $\left(8.92 \times 10^{9} /\right.$ $\mathrm{L})$ and high-sensitivity $\mathrm{C}$-reactive protein (hs-CRP) level $(144.10 \mathrm{nmol} / \mathrm{L})$ compared with those with IS (WBC count, $7.80 \times 10^{9} / \mathrm{L}, P=0.031$; hs-CRP, $33.42 \mathrm{nmol} / \mathrm{L}$, $P=0.001)$. By contrast, the cholesterol $(4.84 \mathrm{mmol} / \mathrm{L})$, triglyceride $(1.28 \mathrm{mmol} / \mathrm{L})$ and albumin $(18 \mathrm{~g} / \mathrm{L})$ levels were significantly lower in patients with $\mathrm{ICH}$ compared with those in patient with IS (cholesterol, $5.74 \mathrm{mmol} / \mathrm{L}$, $P=0.004$; triglyceride, $1.60 \mathrm{mmol} / \mathrm{L}, P<0.001$; albumin, $24 \mathrm{~g} / \mathrm{L}, P=0.009$ ).

\section{Demographic characteristics and clinical course among patients with IS}

Of 233 patients with NS who had been hospitalized for acute IS, 43 (18.5\%) had large-artery atherosclerosis; 23 (9.9\%), cardioembolism; 117 (50.2\%), small-artery occlusion; 11 (4.7\%), stroke of other determined etiology; and 39 (16.7\%), stroke of undetermined etiology. Patient characteristics and clinical course are summarized in Table 2 and Supplementary Table 3. The prevalence of atrial fibrillation was higher in the cardioembolism group $(87.0 \%, P<0.001)$; the prevalence of diabetes mellitus was higher in the small-artery occlusion $(80.3 \%)$ and large-artery atherosclerosis $(69.8 \%)$ groups $(P<$ $0.001)$; the prevalence of modified Rankin scale score $\geqq 3$ upon discharge was higher in the cardioembolism $(78.3 \%)$, stroke of undetermined etiology $(76.9 \%)$, and large-artery atherosclerosis $(76.7 \%)$ groups $(P=0.002)$. Of the female IS patients (total 88 patients), the 30-day mortality rate was $2.3 \%$ (2 patients died); whereas of the male IS patient (total 145 patients), the 30-day mortality was $4.1 \%$ (6 patients died). There was no significant sex difference in patients with IS $(P=0.361$, odds ratio for male $=1.86,95 \%$ confidence interval 0.37-9.41).

\section{Demographic characteristics and clinical course among patients with ICH}

Of 57 patients with NS who had been hospitalized for $\mathrm{ICH}, 45$ (78.9\%) had IH; 4 (7.0\%), SAH; 7 (12.3\%), subdural hemorrhage; and 1 (1.8\%), arteriovenous malformation with bleeding. Patient characteristics and outcomes are presented in Table 3 and Supplementary 
Table 1 Demographic features of nephrotic syndrome patients with stroke

\begin{tabular}{|c|c|c|c|c|}
\hline & $\begin{array}{l}\text { Ischemic stroke } \\
(n=233)\end{array}$ & $\begin{array}{l}\text { Intracranial hemorrhage } \\
(n=57)\end{array}$ & $\begin{array}{l}\text { Odds ratio } \\
\text { ( } 95 \% \text { confidence interval) }\end{array}$ & $P$ value \\
\hline Age (years) & $61(52-71)$ & $57(52-69)$ & & 0.446 \\
\hline Male (\%) & $145(62.2)$ & $35(61.4)$ & $1.04(0.57-1.88)$ & 0.512 \\
\hline \multicolumn{5}{|l|}{ Risk factors } \\
\hline Hypertension (\%) & $195(83.7)$ & $47(82.5)$ & $1.09(0.51-2.35)$ & 0.479 \\
\hline Diabetes mellitus (\%) & $152(65.2)$ & $30(52.6)$ & $1.69(0.94-3.03)$ & 0.055 \\
\hline Hyperlipidemia (\%) & $149(63.9)$ & $17(29.8)$ & $4.17(2.23-7.82)$ & $<0.001 \dagger$ \\
\hline Coronary artery disease (\%) & $35(15)$ & $8(14)$ & $1.08(0.47-2.48)$ & 0.520 \\
\hline Congestive heart failure (\%) & $32(13.7)$ & $9(15.8)$ & $0.85(0.38-1.90)$ & 0.414 \\
\hline Atrial fibrillation (\%) & $24(10.3)$ & $4(7)$ & $1.52(0.51-4.57)$ & 0.320 \\
\hline Hyperuricemia (\%) & $40(17.2)$ & $4(7)$ & $2.75(0.94-8.02)$ & $0.037 \dagger$ \\
\hline Old stroke (\%) & $77(33)$ & $17(29.8)$ & $1.16(0.62-2.18)$ & 0.383 \\
\hline Smoking (\%) & $22(9.4)$ & $1(1.8)$ & $5.84(0.77-44.26)$ & $0.037+$ \\
\hline \multicolumn{5}{|l|}{ Lab data } \\
\hline White blood cells $\left(\times 10^{9} / L\right)$ & $7.80(6.21-9.25)$ & $8.92(6.95-11.02)$ & & $0.031^{*}$ \\
\hline High-sensitivity C-reactive protein ( $\mathrm{nmol} / \mathrm{L})$ & $33.42(14.48-120.10)$ & $144.10(56.29-330.76)$ & & $0.001^{*}$ \\
\hline Total cholesterol (mmol/L) & $5.74(4.24-6.85)$ & $4.84(3.39-6.31)$ & & $0.004^{*}$ \\
\hline Triglyceride $(\mathrm{mmol} / \mathrm{L})$ & $1.60(1.07-2.73)$ & $1.28(0.95-1.71)$ & & $<0.001^{*}$ \\
\hline Albumin (g/L) & $24(11-31)$ & $18(15-29)$ & & $0.009^{*}$ \\
\hline
\end{tabular}

Data are presented as median (interquartile range) or absolute numbers (percentage)

${ }^{*} P<0.05$, Mann-Whitney $U$ test; $+P<0.05$, Chi-square test

Table 4. The 30-day mortality was the highest in the SAH group $(75 \%, P=0.036)$. The prevalence of modified Rankin scale score $\geqq 3$ upon discharge was higher in the IH group (97.8\%, $P<0.001)$.

\section{Survival analysis of mortality in patients with any stroke} During the 30-day observation period, 21 patients died $(21 / 290=7.2 \%)$, including $8(3.4 \%)$ patients with IS and $13(22.8 \%)$ patients with $\mathrm{ICH}$. The causes of patients' death in IS included sepsis (3 patients), pneumonia (2 patients), large infarction with brainstem compression (1 patient), acute myocardial infarction (1 patient), and cardiac arrhythmia (1 patient). The causes of death in patients with $\mathrm{ICH}$ were brainstem dysfunction (10 patients) and sepsis (3 patients). The KaplanMeier analysis showed that patients with $\mathrm{ICH}$ had a higher mortality rate compared with those with IS (log-rank test, $P<0.001$, Fig. 1 ).

\section{Determinants for mortality in patients with any stroke}

The univariate Cox regression indicated that low lipid level, coronary artery disease (CAD), congestive heart failure, pneumonia, $\mathrm{ICH}$, and IS presented as total anterior circulation syndrome (TACS) were potential risk factors $(P<0.1)$ for the 30 -day all-cause mortality. The multivariate Cox proportional hazards model still showed $\mathrm{CAD}, \mathrm{ICH}$, and TACS as significant risk factors for the 30-day all-cause mortality after adjusting for these variables (Table 4 and Supplementary Table 5).

\section{Determinants of mortality in patients with IS}

The univariate Cox regression revealed that CAD, congestive heart failure, TACS, pneumonia, and elevated hs-CRP level were positively associated, while hyperlipidemia was negatively associated with 30-day mortality among NS patients with IS. After adjusting for these potential risk factors $(P<0.1)$ in a backward multivariate Cox proportional hazards model, only CAD was positively associated with 30-day mortality in NS patients with IS (Table 5 and Supplementary Table 6).

\section{Determinants of mortality in patients with $\mathrm{ICH}$}

The univariate Cox regression revealed that CAD and SAH were positively associated, while male sex was negatively associated with 30-day mortality among NS patients with IS. After adjusting for these potential risk factors $(P<0.1)$ backward multivariate Cox proportional hazards model, CAD and SAH were positively associated with 30-day mortality in NS patients with ICH (Table 5 and Supplementary Table 7).

\section{Discussion}

As previous limited studies suggest that the incidence rates of IS and $\mathrm{ICH}$ both increase in patients with NS 
Table 2 Demographic features and clinical courses of nephrotic syndrome patients with ischemic stroke

\begin{tabular}{|c|c|c|c|c|c|c|}
\hline \multirow[t]{2}{*}{ Subtypes } & \multicolumn{5}{|c|}{ All ischemic stroke $(n=233)$} & \multirow[t]{2}{*}{$P$ value } \\
\hline & $\begin{array}{l}\text { Large-artery } \\
\text { atherosclerosis } \\
(n=43)\end{array}$ & $\begin{array}{l}\text { Cardioembolism } \\
(n=23)\end{array}$ & $\begin{array}{l}\text { Small-artery } \\
\text { occlusion } \\
(n=117)\end{array}$ & $\begin{array}{l}\text { Stroke of other } \\
\text { determined } \\
\text { etiology }(n=11)\end{array}$ & $\begin{array}{l}\text { Stroke of } \\
\text { undetermined } \\
\text { etiology }(n=39)\end{array}$ & \\
\hline Age (years) & $58(50-73)$ & $68(61-76)$ & $60(54-69)$ & $35(29-42)$ & $63(53-71)$ & $<0.001^{*}$ \\
\hline Male (\%) & $25(58.1)$ & $16(69.6)$ & $74(63.2)$ & $6(54.5)$ & $24(61.5)$ & 0.883 \\
\hline \multicolumn{7}{|l|}{ Risk factors (\%) } \\
\hline Hypertension (\%) & $38(88.4)$ & $21(91.3)$ & $100(85.4)$ & $7(63.6)$ & $29(74.4)$ & 0.105 \\
\hline Diabetes mellitus (\%) & $30(69.8)$ & $7(30.4)^{\dagger}$ & $94(80.3)^{\dagger}$ & $1(9.1)^{\dagger}$ & $20(51.3)$ & $<0.001+$ \\
\hline Hyperlipidemia (\%) & $30(69.8)$ & $7(30.4)^{\dagger}$ & $81(69.2)$ & $6(54.5)$ & $25(64.1)$ & $0.008+$ \\
\hline Coronary artery disease (\%) & $36(83.7)$ & $6(26.1)$ & $19(16.2)$ & $0(0)$ & $7(17.9)$ & 0.151 \\
\hline Congestive heart failure (\%) & $8(18.6)$ & $6(26.1)$ & $12(10.3)$ & $1(9.1)$ & $5(12.8)$ & 0.263 \\
\hline Atrial fibrillation (\%) & $0(0)$ & $20(87.0)^{\dagger}$ & $2(1.7)^{\dagger}$ & $0(0)$ & $1(2.6)$ & $<0.001+$ \\
\hline Hyperuricemia (\%) & $10(23.3)$ & $8(34.8)$ & $13(11.1)$ & $3(27.3)$ & $6(15.4)$ & $0.040 \dagger$ \\
\hline Old stroke (\%) & $18(41.9)$ & $6(26.1)$ & $36(30.8)$ & $3(27.3)$ & $14(35.9)$ & 0.627 \\
\hline Smoking (\%) & $4(9.3)$ & $0(0)$ & $15(12.8)$ & $0(0)$ & $3(7.7)$ & 0.263 \\
\hline $\begin{array}{l}\text { Mean length of stay in the acute } \\
\text { medicine ward(day) }\end{array}$ & $14(10-21)$ & $19(9-29)$ & $9(6-13)$ & $12(6-20)$ & $13(9-19)$ & $<0.001^{*}$ \\
\hline \multicolumn{7}{|l|}{ Complication at admission } \\
\hline Pneumonia (\%) & $12(27.9)$ & $5(21.7)$ & $11(9.4)$ & $1(9.1)$ & $11(28.2)$ & $0.013+$ \\
\hline Gastrointestinal bleeding (\%) & $5(11.6)$ & $2(8.7)$ & $5(4.3)$ & $1(9.1)$ & $8(20.5)$ & $0.043+$ \\
\hline Urinary tract infection (\%) & $5(11.6)$ & $6(26.1)$ & $12(10.3)$ & $1(9.1)$ & $5(12.8)$ & $<0.001+$ \\
\hline $\begin{array}{l}\text { Modified Rankin scale score } \geqq 3 \text { upon } \\
\text { discharge }(\%)\end{array}$ & $33(76.7)$ & $18(78.3)$ & $67(57.3)$ & $3(27.3)$ & $30(76.9 \%)$ & $0.002+$ \\
\hline Death within 30 days (\%) & $4(9.3)$ & $1(4.3)$ & $2(1.7)$ & $0(0)$ & $1(2.6)$ & 0.195 \\
\hline
\end{tabular}

Data are presented as median (interquartile range) or absolute numbers (percentage)

${ }^{*} P<0.05$, Kruskal-Wallis test; $+P<0.05$, Chi-square test

compared with those of the general population, it is important to identify the factors associated with these two types of stroke in NS. To our knowledge, this study is the largest study done specifically in NS patients with stroke. Our results demonstrated that the prevalence rates of hyperlipidemia, hyperuricemia, and smoking were significantly higher in patients with IS compared with those in patients with ICH. Lines of evidence suggest that lower cholesterol level increases the risk of ICH $[25,26]$. However, the association between cholesterol and risk of IS remains undetermined. A number of reports suggest that cholesterol, high-density lipoprotein cholesterol, and triglycerides are not significantly associated with IS risk [27, 28]. By contrast, one large previous cohort study of healthy women suggests that cholesterol and low-density lipoprotein cholesterol are significantly associated with increased risk of IS [29]. Interestingly, a prospective study demonstrates a positive association of cholesterol with the risk of IS in men, and an inverse association of cholesterol with $\mathrm{IH}$ in women [30]. In NS patients with IS, the prevalence of hyperlipidemia was higher in large-artery atherosclerosis and small-artery occlusion when compared to cardioembolism. In NS patients with $\mathrm{ICH}$, the association between hyperlipidemia and the subtypes of ICH was not significant. Other risk factors for stroke in patients with NS, including the higher prevalence of smoking and hyperuricemia in patients with IS, are consistent with those of the global populations [31-35].

Comparisons of the risk factors between IS and $\mathrm{ICH}$ in general population had been performed in previous studies, but the results remained inconclusive. Factors favoring IS versus ICH which have been described in previous studies included DM [36-38], AF [37-39], previous myocardial infarction [37, 38], previous stroke [37], intermittent arterial claudication [37, 39], obesity [36], hypertension [39], and hyperlipidemia [40]. On the other hand, factors favoring ICH versus IS included smoking [37], alcohol consumption [37, 38], and hypertension [38, 40]. In patients with NS, the prevalence of hyperlipidemia, hyperuricemia, and smoking were significantly higher in IS when compared to ICH. Reduction of cholesterol and uric acid levels, and cassation of cigarette smoking would be important to prevent IS in patients with NS.

Our study also finds higher WBC count and hs-CRP levels as well as lower albumin levels in patients with 
Table 3 Demographic features and clinical courses of nephrotic syndrome patients with intracranial hemorrhage

\begin{tabular}{|c|c|c|c|c|c|}
\hline \multirow[t]{2}{*}{ Types of hemorrhage } & \multicolumn{4}{|c|}{ Any intracranial hemorrhage $(n=57)$} & \multirow[t]{2}{*}{$P$ value } \\
\hline & $\begin{array}{l}\text { Intracerebral } \\
\text { hemorrhage }(n=45)\end{array}$ & $\begin{array}{l}\text { Subarachnoid } \\
\text { hemorrhage }(n=4)\end{array}$ & $\begin{array}{l}\text { Subdural } \\
\text { hemorrhage }(n=7)\end{array}$ & $\begin{array}{l}\text { Arteriovenous } \\
\text { malformation }(n=1)\end{array}$ & \\
\hline Age (years) & $57(52-63)$ & $59(38-76)$ & $70(57-81)$ & 29 & 0.064 \\
\hline Male (\%) & $27(60)$ & $2(50)$ & $5(71.4)$ & $1(100)$ & 0.757 \\
\hline \multicolumn{6}{|l|}{ Risk factors } \\
\hline Hypertension (\%) & $39(86.7)$ & $3(75)$ & $5(71.4)$ & $0(0)$ & 0.112 \\
\hline Diabetes mellitus (\%) & $25(55.6)$ & $1(25)$ & $4(57.1)$ & $0(0)$ & 0.467 \\
\hline Hyperlipidemia (\%) & $14(31.1)$ & $2(50)$ & $1(14.3)$ & $0(0)$ & 0.563 \\
\hline Coronary artery disease (\%) & $7(15.6)$ & $0(0)$ & $1(14.3)$ & $0(0)$ & 0.825 \\
\hline Congestive heart failure (\%) & $8(17.8)$ & $0(0)$ & $1(14.3)$ & $0(0)$ & 0.781 \\
\hline Atrial fibrillation (\%) & $4(8.9)$ & $0(0)$ & $0(0)$ & $0(0)$ & 0.766 \\
\hline Hyperuricemia (\%) & $3(6.7)$ & $1(25)$ & $0(0)$ & $0(0)$ & 0.458 \\
\hline Smoking (\%) & $1(2.2)$ & $0(0)$ & $0(0)$ & $0(0)$ & 0.965 \\
\hline $\begin{array}{l}\text { Mean length of stay in the acute } \\
\text { medicine ward (day) }\end{array}$ & $15(11-28)$ & $22(18-48)$ & $9(8-14)$ & 16 & 0.154 \\
\hline $\begin{array}{l}\text { Modified Rankin Scale score } \geqq 3 \\
\text { upon discharge }(\%)\end{array}$ & $44(97.8)$ & $3(75)$ & $4(57.1)$ & $0(0)$ & $<0.001^{*}$ \\
\hline Death within 30 days (\%) & $10(22.2)$ & $3(75)$ & $0(0)$ & $0(0)$ & $0.036^{*}$ \\
\hline Score of hemorrhage severity (\%) & $\begin{array}{l}\text { Intracerebral } \\
\text { hemorrhage score: } \\
\text { All: } 2(1-3) \\
\text { Death: } 3(3-4) \\
\text { Non-death:1 (1-3) }\end{array}$ & $\begin{array}{l}\text { Hunt and Hess } \\
\text { scale score: } \\
\text { All: } 4 \text { (2-4) } \\
\text { Death: } 4 \text { (4-4) } \\
\text { Non-death: } 2 \text { (2-2) }\end{array}$ & & & \\
\hline
\end{tabular}

Data are presented as median (interquartile range) or absolute numbers (percentage) ${ }^{*} P<0.05$, Chi-square test

ICH compared with those in patients with IS. Infectionunrelated elevation of WBC count can be observed at the early phase after ICH [41-43]. High WBC counts may be also associated with IS in patients with CAD [44]. Higher hs-CRP level predicts further cerebral ischemic events in patients with IS [45] and early hematoma growth and neurological worsening in patients with $\mathrm{IH}$ [46]. It has been shown that patients with large stroke volume have high WBC count and CRP levels in the acute phase of stroke [47]. Consistent with a previous finding [34, 35], we demonstrated that the albumin levels in patients with IS are higher than in those with $\mathrm{ICH}$.

Small-artery occlusion $(50.2 \%)$ is the leading cause of IS in patients with NS. The lower mortality rate in patients with small-artery occlusion also significantly contributes to the relatively low mortality in all patients with IS. Atrial fibrillation is the major cause of cardioembolic stroke [48] and frequently seen in cardioembolism (87\%) in NS patients with IS. Systemic lupus erythematosus, which is associated with both IS and $\mathrm{ICH}$ [49], is frequently seen in stroke of other determined etiology (54.5\%) in NS patients with IS.

Our results show that the mean duration of acute ward stay, percentage of dependent functional outcome (modified Rankin scale score $\geqq 3$ ), and 30-day mortality are higher in patients with ICH (subtypes: IH and SAH) than in those with IS. These findings suggest that the severity of $\mathrm{ICH}$ in patients with NS is greater, accompanied with worse outcome, than in patients with IS. The clinical characteristics and outcome of patients with NS and ICH were seldom reported. Only one study demonstrates 15 patients with ICH and NS [11]. In this study, more than half of the patients presented with comatose status, and a majority of NS patients with $\mathrm{ICH}$ had a poor prognosis [11]. Our study, which recruited 57 patients with $\mathrm{ICH}$, demonstrates that $\mathrm{SAH}$ and $\mathrm{IH}$ had higher mortality than other ICH subtypes $(75 \%$ and $22.2 \%$, respectively). In general population, the mortality rates of SAH divided by the Hunt and Hess scale score were $3 \%$ for Hunt and Hess grade 1 or $2,9 \%$ for grade 3, $24 \%$ for grade 4 , and $71 \%$ for grade 5 [50]. In our study, all patients with Hunt and Hess grade 4 died, suggesting the worse survival in NS patients with SAH. The multivariate Cox regression analysis further confirms the correlation of SAH with 30-day mortality in NS patients with $\mathrm{ICH}$.

Our results show that $\mathrm{CAD}, \mathrm{ICH}$ and IS presented as TACS were associated with the 30-day mortality in NS patients with any type of stroke. The association between carotid atherosclerosis and CAD has been well 


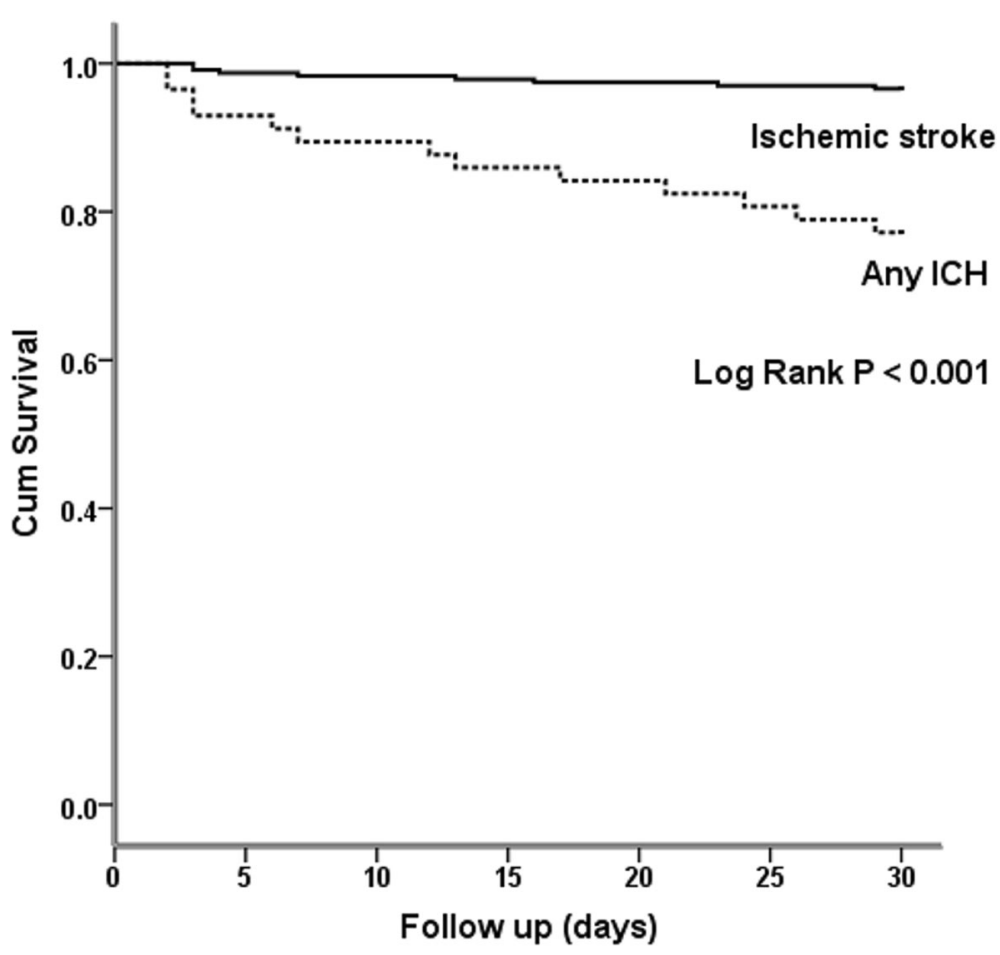

Fig. 1 Kaplan-Meier estimates of patient survival (all-cause mortality) during the 30-day study period. Symbols are as follows: …, any intracranial hemorrhage (ICH); and -, ischemic stroke. Log-rank test, $P<0.001$

established since atherosclerosis is regarded as a systemic disease [51]. The percentage of 30-day mortality in our study is $7.2 \%$, which is similar to a previous study with a small number of patients [11]. The multivariate Cox regression analysis further confirms the correlation of the presence of CAD with either IS or ICH. It is not surprising that TACS, which is usually involved in a large volume of infarction, is associated with poor functional outcome and high all-cause mortality [52].

This study has several limitations. First, there may be a selection bias toward more patients with severe stroke or NS because CG Memorial Hospitals are the largest referral hospitals in Taiwan and have larger proportions of patients with higher disease severity. Second, the data of patients treated in other hospitals were not available in the CG Research Database. Therefore, the dataset may not be able to represent the whole disease group of the overall Taiwanese population. Third, this population-based study has a retrospective design, which may have introduced some confounding factors that could influence the analysis. Fourth, we did not compare IS versus non-IS or ICH versus non-ICH in patients with NS, and may not identify the risk factors for both stroke types. Fifth, the outcome events per predictor variable in the multivariate Cox regression model of our study was relatively stretched. However, one previous study suggested that the rule of ten events per predictor variable in Cox regression might be safely relaxed but

Table 4 Cox regression analysis of patient survival during the 30-day period, intracranial hemorrhage vs. ischemic stroke

\begin{tabular}{|c|c|c|c|c|}
\hline & \multicolumn{2}{|c|}{ Univariate Cox regression } & \multicolumn{2}{|c|}{ Multivariate Cox regression } \\
\hline & HR (95\% Cl) & $P$ value & HR (95\% CI) & $P$ value \\
\hline Hyperlipidemia & $0.22(0.08-0.60)$ & $0.003^{*}$ & & \\
\hline Coronary artery disease & $3.12(1.26-7.72)$ & $0.014^{*}$ & $4.19(1.67-10.46)$ & $0.002+$ \\
\hline Congestive heart failure & $2.58(1.00-6.65)$ & $0.050^{*}$ & & \\
\hline Pneumonia & $3.66(1.54-8.68)$ & $0.003^{*}$ & & \\
\hline Intracranial hemorrhage & $7.33(3.04-17.70)$ & $<0.001^{*}$ & $10.68(3.31-34.47)$ & $<0.001 \dagger$ \\
\hline Total anterior circulation syndrome & $4.82(1.62-14.34)$ & $0.005^{*}$ & $17.65(4.37-71.23)$ & $<0.001 \dagger$ \\
\hline
\end{tabular}

$H R$ Indicates hazard ratio, $\mathrm{Cl}$ Confidence interval

${ }^{*} P<0.1$ for the univariate Cox regression, and $+P<0.05$ for the multivariate Cox regression 
Table 5 Cox regression analysis of patient survival during the 30-day period in nephrotic syndrome patients with stroke

\begin{tabular}{llll}
\hline Variables & $\begin{array}{l}\text { Univariate Cox regression, } \\
\text { HR (95\% Cl) }\end{array}$ & $P$ value & $\begin{array}{l}\text { Multivariate Cox regression, } \\
\text { HR (95\% Cl) }\end{array}$ \\
\hline $\begin{array}{lll}\text { Ischemic stroke } \\
\text { Hyperlipidemia }\end{array}$ & $0.18(0.04-0.91)$ & $0.037^{*}$ & \\
$\quad$ Coronary artery disease & $3.50(0.84-14.64)$ & $0.086^{*}$ & $24.58(1.48-408.90)$ \\
Congestive heart failure & $3.83(0.92-16.02)$ & $0.066^{*}$ & \\
Total anterior circulation syndrome & $16.41(4.10-65.72)$ & $<0.001^{*}$ & \\
Pneumonia & $8.34(1.99-34.92)$ & $0.004^{*}$ & \\
High-sensitivity C-reactive protein & $1.04(1.02-1.06)$ & $<0.001^{*}$ & \\
Intracranial hemorrhage & & & \\
Male & $0.37(0.12-1.12)$ & $0.078^{*}$ & \\
Coronary artery disease & $3.93(1.20-12.85)$ & $0.023^{*}$ & $5.49(1.54-19.56)$ \\
Subarachnoid hemorrhage & $4.23(1.15-15.52)$ & $0.030^{*}$ & $6.32(1.57-25.53)$ \\
\hline
\end{tabular}

$H R$ Indicates hazard ratio, $\mathrm{Cl}$ Confidence interval

${ }^{*} P<0.1$ for the univariate Cox regression, and $+P<0.05$ for the multivariate Cox regression

should be interpreted with caution [53]. Sixth, the details of NS (e.g., staging of chronic kidney disease, immunosuppressive therapies, blood pressure medications, and treatment response, etc.), were not available in most patients of the CG Research Databases.

\section{Conclusions}

NS patients with acute ICH are associated with significantly higher 30-day all-cause mortality compared with those with acute IS. Therefore, the use of antithrombotic agents for IS prevention should be cautious in patients with numerous cerebral microbleeds or cerebral aneurysms with high bleeding risk since the 30-day mortality is high in these patients if $\mathrm{ICH}$ occurs.

\section{Abbreviations}

NS: Nephrotic syndrome; IS: Ischemic stroke; ICH: Intracranial hemorrhage: CG: Chang Gung; IH: Intracerebral hemorrhage; SAH: Subarachnoid hemorrhage; WBC: White blood cell; hs-CRP: High-sensitivity C-reactive protein; CAD: Coronary artery disease; TACS: Total anterior circulation syndrome

\section{Supplementary Information}

The online version contains supplementary material available at https://doi. org/10.1186/s12882-021-02415-w.

Additional file 1: Supplementary Figure 1. Flow of study selection. NS indicates nephrotic syndrome; IS, ischemic stroke; ICH, intracranial

hemorrhage. Supplementary Table 1. The numbers of missing laboratory data. Supplementary Table 2. Demographic features of nephrotic syndrome patients with stroke (additional data). Supplementary Table 3. Demographic features and clinical courses of nephrotic syndrome patients with ischemic stroke (additional data). Supplementary Table 4. Demographic features and clinical courses of nephrotic syndrome patients with intracranial hemorrhage (additional data). Supplementary Table 5. Cox regression analysis of patient survival during the 30-day period, intracranial hemorrhage vs. ischemic stroke (detailed items). Supplementary Table 6. Cox regression analysis of patient survival during the 30-day period in nephrotic syndrome patients with ischemic stroke (detailed items). Supplementary Table 7. Cox regression analysis of patient survival during the 30-day period in nephrotic syndrome patients with intracranial hemorrhage (detailed items).

\section{Acknowledgements}

We gratefully acknowledge Habibzadeh F, Clark TG, Bradburn MJ, Love SB, Altman DG, Ranganathan P, Pramesh CS, and Aggarwal R for the methods of statistical analysis and have cited their manuscripts in references 22-24. We also gratefully acknowledge all staff of the department of neurology and nephrology in CG Memorial Hospital.

\section{Authors' contributions}

WYH, CWC and KHC contributed to the conception, design of the work, and drafted the paper. $\mathrm{KHC}, \mathrm{CMC}, \mathrm{CHC}, \mathrm{HCW}$ and $\mathrm{KHC}$ contributed to acquisition, interpretation and critically revised manuscript. WYH and CWC contributed to analysis of data. All authors critically revised the manuscript for important intellectual content, approved the final version submitted and agreed to be accountable for all aspects of the work.

\section{Funding}

This work was supported by CG Memorial Hospital, grant number: CMRP G2J0121, CMRPG2K0031 and CLRPG3D0048.

\section{Availability of data and materials}

The dataset analyzed during the current study are available from the corresponding author on reasonable request.

\section{Declarations}

\section{Ethics approval and consent to participate}

The experimental procedure of this clinical study was performed under a protocol approved by the Medical Ethics Committee of CG Memorial Hospital, Taipei, Taiwan in accord with the Helsinki Declaration of 1975 (the IRB approval number: 202001012B0). As all data were anonymized from existing databases and results were presented in aggregate, the requirement for informed consent was waived. The no requirement of informed consent was approved by the Medical Ethics Committee of CG Memorial Hospital, Taipei, Taiwan.

\section{Consent for publication}

Not applicable.

\section{Competing interests}

The authors declare that they have no competing interests.

\section{Author details}

'Department of Neurology, Chang Gung University College of Medicine, Chang Gung Memorial Hospital, Keelung Branch, No.222, Mai-Jin Road, 204 Keelung, Taiwan. ${ }^{2}$ Department of Neurology, Chang Gung University College of Medicine, Chang Gung Memorial Hospital, Linkou Branch, 5, Fu Hsing Street, 333 Taoyuan, Taiwan. ${ }^{3}$ Kidney Research Center, Chang Gung Memorial 
Hospital, Linkou Branch, Chang Gung University, School of Medicine, 5, Fu Hsing Street, Taoyuan 333, Taiwan.

\section{Received: 3 November 2020 Accepted: 13 May 2021 Published online: 05 June 2021}

\section{References}

1. Mahmoodi BK, ten Kate MK, Waanders F, Veeger NJ, Brouwer JL, Vogt L, Navis G, van der Meer J. High absolute risks and predictors of venous and arterial thromboembolic events in patients with nephrotic syndrome: results from a large retrospective cohort study. Circulation. 2008;117(2):224-30.

2. Loscalzo J. Venous thrombosis in the nephrotic syndrome. N Engl J Med. 2013;368(10):956-8.

3. Gigante A, Barbano B, Liberatori M, Sardo L, Gasperini ML, Rosato E, Cianci $\mathrm{R}$, Amoroso A. Nephrotic syndrome and stroke. Int J Immunopathol Pharmacol. 2013;26(3):769-72.

4. Roy C, Deschaintre Y, Sabbagh R, Roy D, Cardinal H, Bollee G. Ischemic stroke of possible embolic etiology associated with nephrotic syndrome. Kidney Int Rep. 2017;2(5):988-94.

5. Fuh JL, Teng MM, Yang WC, Liu HC. Cerebral infarction in young men with nephrotic syndrome. Stroke. 1992;23(2):295-7.

6. Wang Y, Meng R, Duan J, Liu G, Chen J, Li S, Ji X. Nephrotic syndrome may be one of the important etiologies of cerebral venous sinus thrombosis. J Stroke Cerebrovasc Dis. 2016;25(10):2415-22.

7. Huang JA, Lin CH, Chang YT, Lee CT, Wu MJ. Nephrotic syndrome is associated with increased risk of ischemic stroke. J Stroke Cerebrovasc Dis. 2019;28(11):104322.

8. Iwaki H, Kuriyama M, Neshige S, Takeshima S, Himeno T, Takamatsu K, Shimoe $Y$, Kobayashi H, Nomoto M, Tanaka A. Acute ischemic stroke associated with nephrotic syndrome: incidence and significance retrospective cohort study. eNeurologicalSci. 2015;1(3-4):47-50.

9. Hu P, Zhao XQ, Hu B, Lu L, Deng F, Yuan LP. Spontaneous intracerebral hemorrhage in a pediatric patient with nephrotic syndrome. J Clin Hypertens. 2014;16(3):236-7.

10. Kono R, Iwaki H, Takeshima S, Shimoe Y, Ota S, Kuriyama M. Intracerebral hemorrhage associated with nephrotic syndrome-prevalemce and clinical characteristics. Rinsho Shinkeigaku. 2016;56(3):180-5.

11. Yang M, Pan X, Liang Z, Huang X, Duan M, Cai H, Yu L, Chen L. Clinical features of nephrotic syndrome with cerebral hemorrhage. Med Sci Monit. 2019;25:2179-85.

12. Kinomura M, Maeshima $Y$, Kodera R, Morinaga H, Saito D, Nakao K, Yanai H, Sada K, Sugiyama H, Makino H. A case of immunotactoid glomerulopathy exhibiting nephrotic syndrome successfully treated with corticosteroids and antihypertensive therapy. Clin Exp Nephrol. 2009;13(4):378-84.

13. Paydas S, Paydas S, Ergin M. Colchicine therapy in amyloidosis related with plasmacytic castleman disease presenting with nephrotic syndrome. Saudi J Kidney Dis Transpl. 2015;26(5):992-5.

14. Solak Y, Polat I, Atalay H, Turk S. When urine is no longer beneficial: renal artery embolisation in severe nephrotic syndrome secondary to amyloidosis. Amyloid. 2010;17(1):24-6.

15. Kapoor K, Saha A, Thakkar D, Dubey NK, Vani K. Meningitis and intracranial bleed in a child with steroid-resistant nephrotic syndrome. Saudi J Kidney Dis Transpl. 2015;26(6):1270-3.

16. Kitamura S, Misawa M, Namba S, Tsuji K, Torigoe R, Shima M, Makino H. Membranous nephropathy with acquired factor $v$ inhibitor: a case report. BMC Res Notes. 2013;6:553.

17. Shao SC, Chan YY, Kao Yang YH, Lin SJ, Hung MJ, Chien RN, Lai CC, Lai EC. The Chang Gung Research Database-a multi-institutional electronic medical records database for real-world epidemiological studies in taiwan. Pharmacoepidemiol Drug Saf. 2019;28(5):593-600.

18. Tsai MS, Lin MH, Lee CP, Yang YH, Chen WC, Chang GH, Tsai YT, Chen PC, Tsai YH. Chang Gung Research Database: a multi-institutional database consisting of original medical records. Biomed J. 2017:40(5):263-9.

19. Adams HP, Jr., Bendixen BH, Kappelle LJ, Biller J, Love BB, Gordon DL, Marsh $\mathrm{EE}, 3 \mathrm{rd}$. Classification of subtype of acute ischemic stroke. Definitions for use in a multicenter clinical trial. Toast. Trial of org 10172 in acute stroke treatment Stroke 1993:24(1):35-41.

20. Bamford J, Sandercock P, Dennis M, Burn J, Warlow C. Classification and natural history of clinically identifiable subtypes of cerebral infarction. Lancet. 1991;337(8756):1521-6.
21. Hemphill JC, 3rd, Bonovich DC, Besmertis L, Manley GT, Johnston SC. The CH score: a simple, reliable grading scale for intracerebral hemorrhage. Stroke. 2001;32(4):891-7.

22. Habibzadeh F. Statistical data editing in scientific articles. J Korean Med Sci. 2017; 32(7):1072-6.

23. Kang $\mathrm{H}$. The prevention and handling of the missing data. Korean J Anesthesiol. 2013; 64(5): 402-6.

24. Clark TG, Bradburn MJ, Love SB, Altman DG. Survival analysis part I: basic concepts and first analyses. Br J Cancer. 2003;89(2):232-8.

25. D'Amelio M, Terruso V, Famoso G, Ragonese P, Aridon P, Savettieri G. Cholesterol levels and risk of hemorrhagic transformation after acute ischemic stroke. Cerebrovasc Dis. 2011;32(3):234-8.

26. Wang $X$, Dong $Y$, Qi $X$, Huang $C$, Hou L. Cholesterol levels and risk of hemorrhagic stroke: a systematic review and meta-analysis. Stroke. 2013; 44(7):1833-9.

27. Bowman TS, Sesso HD, Ma J, Kurth T, Kase CS, Stampfer MJ, Gaziano JM. Cholesterol and the risk of ischemic stroke. Stroke. 2003:34(12):2930-4.

28. Saeed E, Ali R, Jalal-ud-din M, Saeed A, Jadoon RJ, Moiz M. Hypercholesterolemia in patients of ischemic stroke. J Ayub Med Col Abbottabad. 2015;27(2):637-9.

29. Kurth T, Everett BM, Buring JE, Kase CS, Ridker PM, Gaziano JM. Lipid levels and the risk of ischemic stroke in women. Neurology. 2007;68(8):556-62.

30. Zhang Y, Tuomilehto J, Jousilahti P, Wang Y, Antikainen R, Hu G. Total and high-density lipoprotein cholesterol and stroke risk. Stroke. 2012;43(7):1768-74.

31. Pan B, Jin X, Jun L, Qiu S, Zheng Q, Pan M. The relationship between smoking and stroke: A meta-analysis. Medicine. 2019;98(12):e14872.

32. Peters SA, Huxley RR, Woodward M. Smoking as a risk factor for stroke in women compared with men: a systematic review and meta-analysis of 81 cohorts, including 3,980,359 individuals and 42,401 strokes. Stroke. 2013; 44(10):2821-8.

33. Shah RS, Cole JW. Smoking and stroke: the more you smoke the more you stroke. Expert Rev Cardiovasc Ther. 2010;8(7):917-32.

34. Storhaug HM, Norvik JV, Toft I, Eriksen BO, Lochen ML, Zykova S, Solbu M, White $\mathrm{S}$, Chadban $\mathrm{S}$, Jenssen T. Uric acid is a risk factor for ischemic stroke and all-cause mortality in the general population: a gender specific analysis from the Tromsø study. BMC Cardiovasc Disord. 2013;13:115.

35. Tariq MA, Shamim SA, Rana KF, Saeed A, Malik BH. Serum uric acid - risk factor for acute ischemic stroke and poor outcomes. Cureus. 2019;11(10): e6007.

36. Price AJ, Wright FL, Green J, Balkwill A, Kan SW, Yang TO, Floud S, Kroll ME, Simpson R, Sudlow CLM, et al. Differences in risk factors for 3 types of stroke: UK prospective study and meta-analyses. Neurology. 2018;90(4):e298e306.

37. Andersen KK, Olsen TS, Dehlendorff C, Kammersgaard LP. Hemorrhagic and ischemic strokes compared: stroke severity, mortality, and risk factors. Stroke. 2009;40(6):2068-72.

38. Tsai CF, Anderson N, Thomas B, Sudlow CL. Comparing risk factor profiles between intracerebral hemorrhage and ischemic stroke in chinese and white populations: systematic review and meta-analysis. PLoS One. 2016; 11(3):e0151743.

39. Bilić I, Dzamonja G, Lusić I, Matijaca M, Caljkusić K. Risk factors and outcome differences between ischemic and hemorrhagic stroke. Acta Clin Croat. 2009:48(4):399-403.

40. Synyasi RDLR, Pinzon RT. Clinical symptoms and risk factors comparison of ischemic and hemorrhagic stroke. Jurnal kedokteran dan kesehatan Indonesia. 2018;9(1):5-15

41. Wang J, Dore S. Inflammation after intracerebral hemorrhage. J Cereb Blood Flow Metab. 2007;27(5):894-908.

42. Yu S, Arima H, Heeley E, Delcourt C, Krause M, Peng B, Yang J, Wu G, Chen $X$, Chalmers J, et al. White blood cell count and clinical outcomes after intracerebral hemorrhage: the interact2 trial. J Neurol Sci. 2016:361:112-6.

43. Yu Z, Zheng J, Guo R, Ma L, You C, Li H. Prognostic impact of leukocytosis in intracerebral hemorrhage: a prisma-compliant systematic review and meta-analysis. Medicine. 2019:98(28):e16281.

44. Koren-Morag N, Tanne D, Goldbourt U. White blood cell count and the incidence of ischemic stroke in coronary heart disease patients. Am J Med. 2005;118(9):1004-9.

45. Arenillas JF, Alvarez-Sabin J, Molina CA Chacon P, Montaner J, Rovira A Ibarra B, Quintana M. C-reactive protein predicts further ischemic events in first-ever transient ischemic attack or stroke patients with intracranial largeartery occlusive disease. Stroke. 2003;34(10):2463-8. 
46. Di Napoli M, Parry-Jones AR, Smith CJ, Hopkins SJ, Slevin M, Masotti L, Campi V, Singh P, Papa F, Popa-Wagner A, et al. C-reactive protein predicts hematoma growth in intracerebral hemorrhage. Stroke. 2014;45(1):59-65.

47. Audebert HJ, Rott MM, Eck T, Haberl RL. Systemic inflammatory response depends on initial stroke severity but is attenuated by successful thrombolysis. Stroke. 2004;35(9):2128-33.

48. Kamel H, Healey JS. Cardioembolic stroke. Circ Res. 2017;120(3):514-26.

49. Ioannidis S, Mavridis M, Mitsias PD. Ischemic stroke as initial manifestation of systemic lupus erythematosus: a case report and review of the literature. eNeurologicalSci. 2018;13:26-30.

50. Lantigua H, Ortega-Gutierrez S, Schmidt JM, Lee K, Badjatia N, Agarwal S, Claassen J, Connolly ES, Mayer SA. Subarachnoid hemorrhage: who dies, and why? Crit Care. 2015;19(1):309.

51. Tanimoto S, Ikari Y, Tanabe K, Yachi S, Nakajima H, Nakayama T, Hatori M, Nakazawa G, Onuma Y, Higashikuni Y, et al. Prevalence of carotid artery stenosis in patients with coronary artery disease in japanese population. Stroke. 2005:36(10):2094-8.

52. Bhaskar S, Stanwell P, Bivard A, Spratt N, Walker R, Kitsos GH, Parsons MW, Evans $\mathrm{M}$, Jordan L, Nilsson M, et al. The influence of initial stroke severity on mortality, overall functional outcome and in-hospital placement at 90 days following acute ischemic stroke: A tertiary hospital stroke register study. Neurol India. 2017;65(6):1252-9.

53. Vittinghoff $E$, McCulloch CE. Relaxing the rule of ten events per variable in logistic and Cox regression. Am J Epidemiol. 2007;165(6):710-8.

\section{Publisher's Note}

Springer Nature remains neutral with regard to jurisdictional claims in published maps and institutional affiliations.

Ready to submit your research? Choose BMC and benefit from:

- fast, convenient online submission

- thorough peer review by experienced researchers in your field

- rapid publication on acceptance

- support for research data, including large and complex data types

- gold Open Access which fosters wider collaboration and increased citations

- maximum visibility for your research: over $100 \mathrm{M}$ website views per year

At $\mathrm{BMC}$, research is always in progress.

Learn more biomedcentral.com/submissions 